\title{
Concomitant CAM and C3 Photosynthetic Pathways in Dendrobium officinale Plants
}

\author{
Zejin Zhang and Dongxian $\mathrm{He}^{1}$ \\ College of Water Resources and Civil Engineering, China Agricultural University, Beijing 100083, \\ China \\ Genhua Niu \\ Texas AgriLife Research at El Paso, Texas A\&M University, 1380 A\&M Circle, El Paso, TX 79927 \\ Rongfu Gao \\ College of Biological Sciences and Technology, Beijing Forestry University, Beijing 100083, China
}

\begin{abstract}
AdDitional INDEX wORDS. $\mathrm{CO}_{2}$ assimilation pattern, crassulacean acid metabolism, drought stress, light-dark cycle
Abstract. Dendrobium officinale, endemic to China, is a rare and endangered medicinal herb. As a result of its high economic value, slow growth, and diminishing wild population, protected cultivation is preferred. However, little information is available on its growing environment and photosynthetic characteristics. In this study, the photosynthetic patterns of $D$. officinale were investigated under various environmental conditions by measuring the net $\mathrm{CO}_{2}$ exchange rates continuously for several days or weeks. Under non-stressed growth chamber conditions with 12-hour light and 12-hour dark periods, $D$. officinale had concomitance of $\mathrm{C} 3$ and crassulacean acid metabolism (CAM) photosynthesis patterns. Different degrees of $\mathrm{CAM}$ in D. officinale, expressed as the percentage of $\mathrm{CO}_{2}$ exchanges in the dark period to the daily amount of $\mathrm{CO}_{2}$ exchanges, were observed depending on environmental conditions. With decreasing substrate water content, a typical CAM pattern was found, and concomitance of C3 and CAM patterns was found again when plants were rewatered. The accumulation of leaf titratable acidity during a dark period increased as substrate dried out but decreased again as plants were rewatered. A shorter light-dark cycle (4-hour light and 4-hour dark periods) led to a C3 pattern alone. The substrate moisture and light-dark cycle were inducible factors for switching between $\mathrm{C} 3$ and CAM patterns in $D$. officinale. These results indicate that $D$. officinale is a facultative CAM plant and the $\mathrm{C} 3$ pathway can be induced by controlling the growing environment. Further studies are needed to identify the optimal environmental conditions to enhance the growth of $D$. officinale.
\end{abstract}

The photosynthetic pathways of $\mathrm{C} 3, \mathrm{C} 4$, and CAM are known to have different photosynthetic properties (Larcher, 1995; Nobel, 1991). Although the dry matter accumulation rate of CAM plants is lower than that of $\mathrm{C} 3$ and $\mathrm{C} 4$ plants, CAM plants have the ability to adapt to extreme environments such as drought, high temperature, and salt stress (Osmond, 1978; Rascher et al., 1998; Winter and Holtum, 2007). Leaf succulence of Aeonium plants is correlated with $\mathrm{CO}_{2}$ assimilation patterns (Larcher, 1995), and the $\mathrm{CO}_{2}$ assimilation pattern of some CAM plants can be strongly regulated by environmental conditions such as light intensity, temperature, soil water content, and photoperiod (Brulfert et al., 1988, 1996; de Mattos and Lüttge, 2001; Maxwell, 2002).

Many epiphytes found in tropical and subtropical forests grow on rocks or tree trunks where water deficit is frequent, and many of them are CAM plants (Silvera et al., 2005). Almost all Dendrobium species are epiphytes. Because of their high ornamental and medicinal values, many Dendrobium species are cultivated in the open field or greenhouses. Only a small percentage of Dendrobium species have been studied for their photosynthetic pathways. Dendrobium taurinum (Fu and Hew, 1982), D. ekapol [sic] (Sekizuka et al., 1992), D. tortile,

Received for publication 17 Oct. 2013. Accepted for publication 12 Feb. 2014. This work is supported by the National Natural Science Foundation of China (Grant No. 31372089).

We thank Guoming Zheng (Beijing Forestry University, China) for providing and maintaining the continuous photosynthetic measurement system.

${ }^{1}$ Corresponding author. E-mail: he_dongxian@hotmail.com.
D. crumenatum (Sinclair, 1984), D. primulinum (Ren et al., 2010), and D. beckleri (Winter et al., 1983) have CAM pathways, whereas $D$. chrysotoxum has a C3 pathway (Ren et al., 2010) based on the diurnal changes of net $\mathrm{CO}_{2}$ change rates, leaf titratable acidity, malic acid, leaf stomatal conductance, and the $\delta^{13} \mathrm{C}$ value.

Dendrobium officinale, endemic to China, is a rare and endangered orchid with extremely slow growth (Su and Zhang, 2003). Its stems have many health benefits such as promotion of the immune system as well as antiaging and anticancer properties (Li et al., 2011). The photosynthesis of D. officinale is affected by temperature (Ai et al., 2010), light quality (Gao et al., 2012), light intensity (Bao et al., 2007), air humidity (Zhang et al., 2013), and other cultural conditions (Mao, 2008). $\mathrm{Su}$ and Zhang (2003) measured the daily changes of net $\mathrm{CO}_{2}$ exchange rates of $D$. officinale under various conditions and determined it was a facultative CAM plant. That is, $D$. officinale had a CAM pattern on sunny days, a C3 pattern on rainy days, and an intermediate pattern between CAM and $\mathrm{C} 3$ on cloudy days. Nevertheless, the specific inducing environmental factors that cause the switching between $\mathrm{C} 3$ and the CAM pathway are still unknown.

Because stomata of a CAM plant are closed during the light period and the malic acid accumulated overnight is broken down to release $\mathrm{CO}_{2}$ that is fixed by ribulose bisphosphate carboxylase/oxygenase (Rubisco) during the light period behind closed stomata, the actual photosynthesis cannot be determined by measuring the gas exchange rates only during a light period or by instantaneous gas exchange rates. The CAM 
contribution to the whole-day carbon assimilation can be determined from the continuous measurement of net $\mathrm{CO}_{2}$ exchange rates of CAM plants for a whole day; thus, the photosynthetic pattern can be accurately determined. The continuous measurement of photosynthesis had been applied for determining the photosynthetic pathway of some obligate and facultative CAM plants such as Clusia rosea, C. cylindrica, and Mesembryanthemum crystallinum (Winter et al., 2009; Winter and Holtum, 2007).

The objectives of this study were to determine the photosynthetic pathway of $D$. officinale and identify the inducing factors for switching between $\mathrm{C} 3$ and the CAM pathway. The effects of drought stress and various light-dark cycles on $\mathrm{CO}_{2}$ assimilation patterns of $D$. officinale and nocturnal accumulation of leaf titratable acidity were also investigated.

\section{Materials and Methods}

Plant materials and culture conditions. Tissue-cultured D. officinale plants were grown in an unheated greenhouse for commercial production in Jinhua city, Zhejiang province (lat. $29^{\circ} 0^{\prime} 14^{\prime} \mathrm{N}$, long. $\left.119^{\circ} 60^{\prime} 32^{\prime \prime} \mathrm{E}\right)$ for 3 years before being transported to China Agricultural University in Beijing (lat. $40^{\circ} 0^{\prime} 25^{\prime \prime} \mathrm{N}$, long. $116^{\circ} 21^{\prime} 27^{\prime \prime} \mathrm{E}$ ) on 29 Apr. 2012. The Jinhua greenhouse annual average air temperature was $17.5^{\circ} \mathrm{C}$, the lowest air temperature was $-2.8^{\circ} \mathrm{C}$, and the highest air temperature was $38.9^{\circ} \mathrm{C}$. The 3 -year-old plants were grown in $0.4-\mathrm{L}$ round plastic pots (two plants per pot) filled with a substrate mix of composted small pine bark ( 3 to $8 \mathrm{~mm}$ ), medium pine bark ( 5 to $10 \mathrm{~mm}$ ), pine bark powder, perlite, and composted sawdust in a volume ratio of $1: 1: 1: 1: 0.5$. Thirty-five pots were kept in a greenhouse with natural light and 25 were kept in a walk-in growth chamber under artificial light. These plants were used for $\mathrm{CO}_{2}$ exchange rate measurement. Plants in both greenhouse and growth chambers were watered with nutrient solution once every 2 to $3 \mathrm{~d}$ as needed. The nutrient solution contained (in mg. $\mathrm{L}^{-1}$ ) $205 \mathrm{Ca}\left(\mathrm{NO}_{3}\right)_{2} \cdot 4 \mathrm{H}_{2} \mathrm{O}, 60 \mathrm{MgSO}_{4} \cdot 7 \mathrm{H}_{2} \mathrm{O}, 136 \mathrm{KH}_{2} \mathrm{PO}_{4}$,
$80 \mathrm{NH}_{4} \mathrm{NO}_{3}, 3.6 \mathrm{MnSO}_{4} \cdot \mathrm{H}_{2} \mathrm{O}, 2.7 \mathrm{H}_{3} \mathrm{BO}_{3}, 13.4 \mathrm{FeSO}_{4} \cdot 7 \mathrm{H}_{2} \mathrm{O}$, $0.1 \mathrm{CuSO}_{4} \cdot 5 \mathrm{H}_{2} \mathrm{O}, 0.4 \mathrm{ZnSO}_{4} \cdot 7 \mathrm{H}_{2} \mathrm{O}$, and $0.1\left(\mathrm{NH}_{4}\right)_{6} \mathrm{Mo}_{7} \mathrm{O}_{24} \cdot 4 \mathrm{H}_{2} \mathrm{O}$.

Measurement System of Net $\mathrm{CO}_{2}$ eXChange Rate. When measuring net $\mathrm{CO}_{2}$ exchange rate of a single leaf using a fluorescence cuvette (6400-40; LI-COR, Lincoln, NE) of the portable photosynthesis system (LI-6400; LI-COR) in the growth chamber, low net $\mathrm{CO}_{2}$ exchange rates [between -2 and $4 \mu \mathrm{mol} \cdot \mathrm{m}^{-2} \cdot \mathrm{s}^{-1}$ every $3 \mathrm{~min}$ (data not shown)] with large fluctuations were observed. Because of the large variation, it was not possible to judge whether the net $\mathrm{CO}_{2}$ exchange rates were positive or negative. By using a conifer cuvette (6400-05; LI-COR) of the same portable photosynthesis system with multiple leaves enclosed, the net $\mathrm{CO}_{2}$ exchange rates had smaller fluctuations with low rates of less than $2 \mu \mathrm{mol} \cdot \mathrm{m}^{-2} \cdot \mathrm{s}^{-1}$. These results indicate that increasing leaf area or biomass within the cuvette can improve the measurement accuracy for species with low photosynthetic rates such as D. officinale. However, from the non-continuously measured net $\mathrm{CO}_{2}$ exchange rates of $D$. officinale by the portable photosynthesis system, the photosynthesis pathway of CAM plants cannot be accurately determined.

To more accurately determine the photosynthetic pathway of $D$. officinale, a continuous photosynthesis measurement system was constructed. The shoots were enclosed in the cuvettes, whereas the container (roots and substrate) was excluded. The system consisted of two gas-tight rectangle acrylic cuvettes, an infrared (IR) $\mathrm{CO}_{2}$ analyzer (GXH-3052; Beijing Beifen-Ruili Analytical Instrument Co., Beijing, China), two air pumps (FML201.5; Chengdu Qihai E\&M Manufacturing Co., Chengdu, China), three mass airflow meters (AWM5102; Honeywell, Morristown, NJ), two connected to the two cuvettes and one to the $\mathrm{CO}_{2}$ analyzer, two cuvette temperature control modules, and an embedded computer (Fig. 1). Each cuvette $(25 \times 15 \times 6 \mathrm{~cm})$ was equipped with a small fan for mixing air, and the airflow was controlled by an air pump forcing the airflow from the cuvette inlet to the outlet. The differential $\mathrm{CO}_{2}$ concentrations of the inlet and outlet were automatically

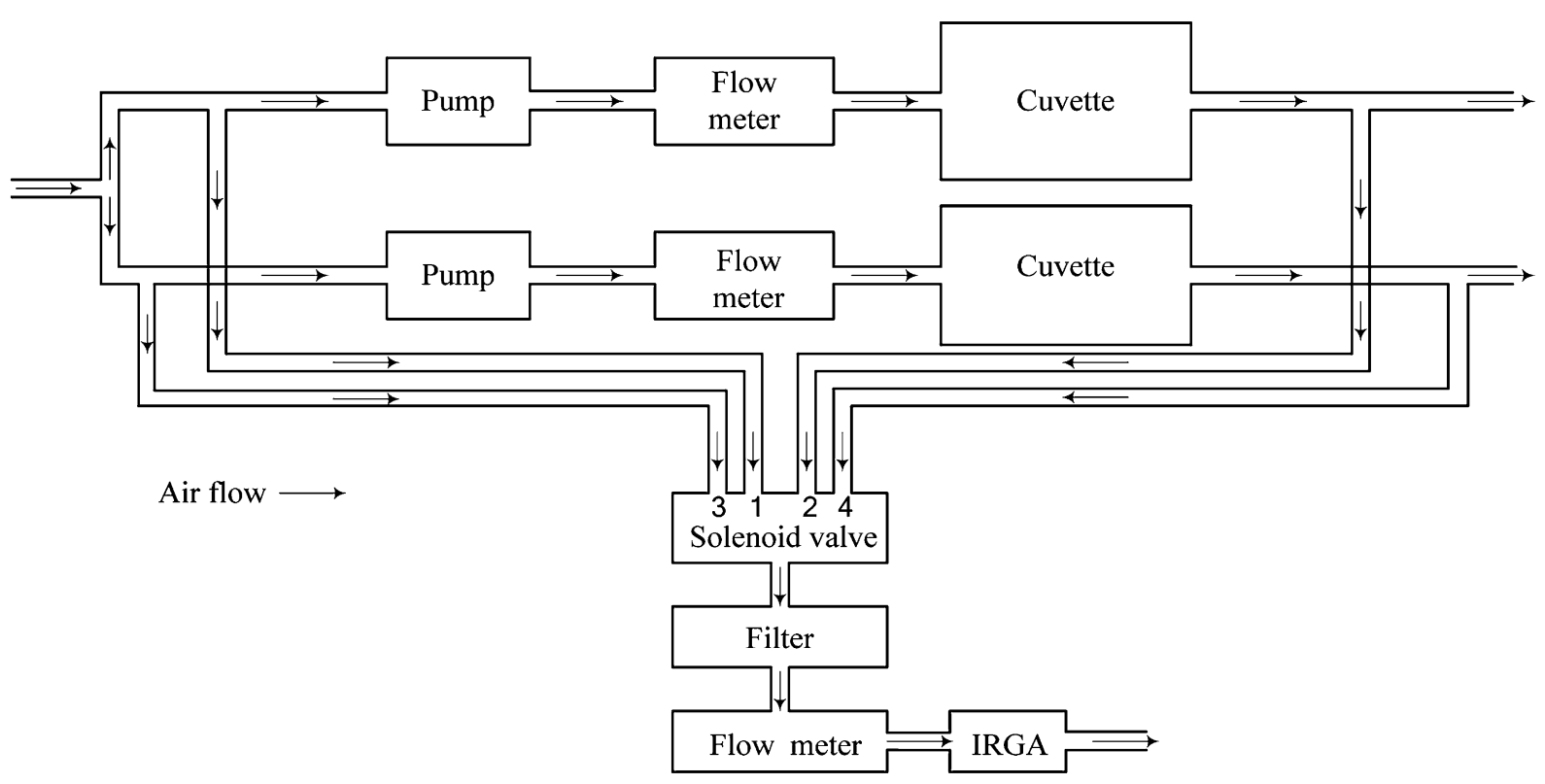

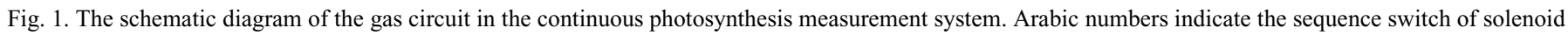
valve. IRGR $=$ infrared $\mathrm{CO}_{2}$ analyzer. 
determined by the IR $\mathrm{CO}_{2}$ analyzer every $105 \mathrm{~s}$ for one cuvette. Carbon dioxide assimilation of each cuvette was measured every $7 \mathrm{~min}$ by switching the four solenoid valves. Photosynthetic photon flux $(P P F)$ at the upper outer surface of the cuvette was measured by a quantum sensor (LI-190SA; LI-COR).

The net $\mathrm{CO}_{2}$ exchange rate $\left(\mu \mathrm{mol} \cdot \mathrm{m}^{-2} \cdot \mathrm{s}^{-1}\right)$ for the plant inside the cuvette is calculated as follows: Net $\mathrm{CO}_{2}$ exchange rate $=\mathrm{k} \times\left(\mathrm{C}_{1}-\mathrm{C}_{2}\right) \times \mathrm{F} / \mathrm{LA}$ where, $\mathrm{k}$ is the conversion coefficient (mol. $\left.\mathrm{L}^{-1}\right) ; \mathrm{C}_{1}$ and $\mathrm{C}_{2}$ are the $\mathrm{CO}_{2}$ concentrations at the inlet and outlet of the cuvette, respectively $\left(\mu \mathrm{mol} \cdot \mathrm{mol}^{-1}\right) ; \mathrm{F}$ is airflow rate $\left(\mathrm{L} \cdot \mathrm{min}^{-1}\right)$; and LA is leaf area $\left(\mathrm{m}^{2}\right)$. LA was determined according to Yang et al. (2002).

The zero calibration of the IR $\mathrm{CO}_{2}$ analyzer was conducted by pumping $\mathrm{CO}_{2}$-free air (passing the air through soda lime) into the IR $\mathrm{CO}_{2}$ analyzer. The $\mathrm{CO}_{2}$ exchange rates of the empty chambers were measured before and after each measurement. The noise level, which is the difference in $\mathrm{CO}_{2}$ concentrations between inlet and outlet of the empty cuvette, was $\pm 3.3 \mu \mathrm{mol} \cdot \mathrm{mol}^{-1}$.

Measurement OF NET $\mathrm{CO}_{2}$ EXChange RATES UNDER VARIOUS ENVIRONMENTAL CONDITIONS. Net $\mathrm{CO}_{2}$ exchange rates were continuously measured using the mentioned system for $2 \mathrm{~d}$ on 23 and 24 Apr. 2012 for plants in the Jinhua commercial greenhouse, 30 and 31 May 2012 for plants in the Beijing research greenhouse, and 2 and 3 Sept. 2012 for plants in the growth chamber. The continuous measurement system allowed monitoring of photosynthetic rates in two cuvettes simultaneously that were averaged for analysis and illustration in figures.

For the walk-in growth chamber at China Agricultural University, the average air temperature was (mean \pm SD) $25 \pm$ $1.0{ }^{\circ} \mathrm{C}$, relative humidity $(\mathrm{RH})$ at $65 \% \pm 5 \%$, and a $12-\mathrm{h}$ photoperiod (24-h light-dark cycle). $\mathrm{CO}_{2}$ concentration was controlled at $500 \pm 50 \mu \mathrm{mol} \cdot \mathrm{mol}^{-1}$ and $P P F$ at canopy level was maintained at $160 \mu \mathrm{mol} \cdot \mathrm{m}^{-2} \cdot \mathrm{s}^{-1}$, provided by fluorescent lamps.

EFFECTS OF DROUGHT AND REWATERING ON NET $\mathrm{CO}_{2}$ EXCHANGE RATE. Two uniform plants of $D$. officinale grown in the growth chambers were selected for measurement. The selected plants were well watered with nutrient solution to container capacity on 5 July 2012. After drainage was completed, shoots were inserted in the cuvettes to initiate the net $\mathrm{CO}_{2}$ exchange rate measurement on 6 July 2012 (Day 1). Irrigation was withheld for the first $12 \mathrm{~d}$. At the end of the light period on Day 12 , plants were rewatered. The net $\mathrm{CO}_{2}$ exchange rates of the two shoots were measured continuously in a growth chamber until 24 July for a total of $18 \mathrm{~d}$.

EFFECT OF DIFFERENT LIGHT AND DARK CYCLES ON NET $\mathrm{CO}_{2}$ EXCHANGE RATE. Net $\mathrm{CO}_{2}$ exchange rates of $D$. officinale increased rapidly after the onset of light, reached the peak in 1 to $2 \mathrm{~h}$, and then gradually decreased. This phenomenon may indicate that much of the net $\mathrm{CO}_{2}$ fixation may occur early in the light period. The original light-dark cycle was $24 \mathrm{~h} \cdot \mathrm{d}^{-1}$ with $12 \mathrm{~h}$ light and $12 \mathrm{~h}$ dark on 27 to 29 Aug. 2012. By shortening the light and dark period cycle, the net $\mathrm{CO}_{2}$ exchanges of D. officinale in a $24-\mathrm{h}$ period may be increased and the $\mathrm{CO}_{2}$ assimilation pattern may be changed. Net $\mathrm{CO}_{2}$ exchange rates of $D$. officinale at shorter cycles (12-h and 8-h cycles with equal length for light and dark periods, that is, $6 \mathrm{~h}$ light and $6 \mathrm{~h}$ dark and $4 \mathrm{~h}$ light and 4 dark, respectively) were measured on 26 to 28 Sept. 2012 and on 20 to 22 Oct. 2012 in the growth chamber. The 1-d time course of net $\mathrm{CO}_{2}$ exchange for $D$. officinale plants under 8-, 12-, and 24-h cycles were presented.
Before the initiation of net $\mathrm{CO}_{2}$ exchange measurement for a different light and dark cycle, plants were grown under the new cycle regimen for $3 \mathrm{~d}$ for acclimatization. Plants were grown in the growth chamber and watered every $3 \mathrm{~d}$. The average air temperature in the growth chamber was maintained at $25 \pm 1.0{ }^{\circ} \mathrm{C}$ and $\mathrm{RH}$ at $65 \% \pm 5 \% . \mathrm{CO}_{2}$ concentration was controlled at $500 \pm 50 \mu \mathrm{mol} \cdot \mathrm{mol}^{-1}$ and $P P F$ at canopy level was $160 \mu \mathrm{mol} \cdot \mathrm{m}^{-2} \cdot \mathrm{s}^{-1}$ provided by fluorescent lamps.

LEAF SAMPLES FOR TITRATABLE ACIDITY ANALYSIS. In addition to the plants that were measured for net $\mathrm{CO}_{2}$ exchange rate, 12 pots ( 24 plants) grown in the growth chamber were selected for relative water content (described subsequently) and another 12 pots for titratable acidity analysis of leaves. Irrigation was withheld for six pots designated as drought treatment, whereas another six pots were well watered and designated as controls. At 2030 HR (30 min after the onset of dark period) on Day 1 (6 July), Day 11, and Day 17 and at $0730 \mathrm{HR}$ (30 min before the onset of light period) on Day 2, Day 12, and Day 18, six leaves (the fourth to sixth leaves of the shoot from the top to bottom) per treatment were sampled from both drought and control (well-watered) plants.

For the different light and dark cycles, leaf samples were taken from the 8-h cycle (4-h light and 4-h dark periods) for titratable acidity analysis. Leaves were sampled at 0400, 0800, 1200, and 2000 HR on 20 Oct. 2012.

DEtermination of Titratable ACIDITy. Leaf samples were cut into small segments and a portion was weighed $(0.6 \mathrm{~g} /$ sample) and ground in $10 \mathrm{~mL}$ distilled water in a mortar. The resultant slurry was transferred to a $100-\mathrm{mL}$ flask that was placed in a boiling water bath for $30 \mathrm{~min}$ to extract the acid. While in the boiling water bath, the sample was mixed several times. The titratable acidity was determined by measuring the volume of $10 \mathrm{~mm} \mathrm{NaOH}$ required to neutralize each sample to $\mathrm{pH}$ 7.0. The titratable acidity in the dark period was determined as the difference between titratable acidities of two consecutive sampling times.

Relative WATER CONTENT OF LEAVES IN THE DROUght TREATMENT. Leaves were sampled on Day 1 (6 July), Day 12 (before rewatering), and Day 18 to quantify leaf water status in the drought treatment. The relative water content (RWC) of plant leaves was calculated as: RWC $(\%)=(\mathrm{FW}-\mathrm{DW}) /(\mathrm{TW}-$ $\mathrm{DW}) \times 100$ where $\mathrm{FW}$ is leaf fresh weight, TW is the turgid weight after the leaves were immersed in water for $24 \mathrm{~h}$, and $\mathrm{DW}$ is the dry weight after oven-drying at $85^{\circ} \mathrm{C}$ for $72 \mathrm{~h}$. The fifth leaf from the shoot tip was sampled for RWC measurement and five leaves were used for each treatment.

Statistical analysis. A one-way analysis of variance was performed to test the significance of drought and well-watered plants on titratable acidity and RWC. All data analyses were run in Excel 2007 (Microsoft Corp., Redmond, WA) and SPSS 18.0 (IBM Corp., Armonk, NY). Unless otherwise noted, $P$ values less than 0.05 were considered statistically significant.

\section{Results and Discussion}

$\mathrm{CO}_{2}$ ASSIMILATION PATTERNS UNDER VARIOUS ENVIRONMENTAL CONDITIONS. The Jinhua commercial greenhouse environment was maintained at an average air temperature of (mean $\pm \mathrm{SD}$ ) $30.2 \pm 5.9^{\circ} \mathrm{C}$ and $\mathrm{RH}$ of $51 \% \pm 12 \%$ during the day and $20.7 \pm$ $4.3{ }^{\circ} \mathrm{C}$ and $62 \% \pm 7 \% \mathrm{RH}$ at night. The Beijing research greenhouse environment was maintained at an average air temperature of $28.1 \pm 4.0^{\circ} \mathrm{C}$ and $\mathrm{RH}$ of $28 \% \pm 12 \%$ during the 
day and $25.3 \pm 2.0^{\circ} \mathrm{C}$ and $32 \% \pm 12 \% \mathrm{RH}$ at night. The maximum $P P F$ on the measurement days in the Jinhua and Beijing greenhouses were 168 and $426 \mu \mathrm{mol} \cdot \mathrm{m}^{-2} \cdot \mathrm{s}^{-1}$, respectively. For the growth chamber, $P P F$ was $163.5 \pm 1.4 \mu \mathrm{mol} \cdot \mathrm{m}^{-2} \cdot \mathrm{s}^{-1}$ and daily average air temperature was $26.2 \pm 1.2{ }^{\circ} \mathrm{C}$.
In the growth chamber with a relatively constant environment, the net $\mathrm{CO}_{2}$ exchange rate of $D$. officinale reached maximums of 3.4 and $3.5 \mu \mathrm{mol} \cdot \mathrm{m}^{-2} \cdot \mathrm{s}^{-1}$ at $1 \mathrm{~h}$ after the transition from dark to light period on 2 and 3 Sept., respectively, then decreased slightly and maintained a positive net $\mathrm{CO}_{2}$ exchange
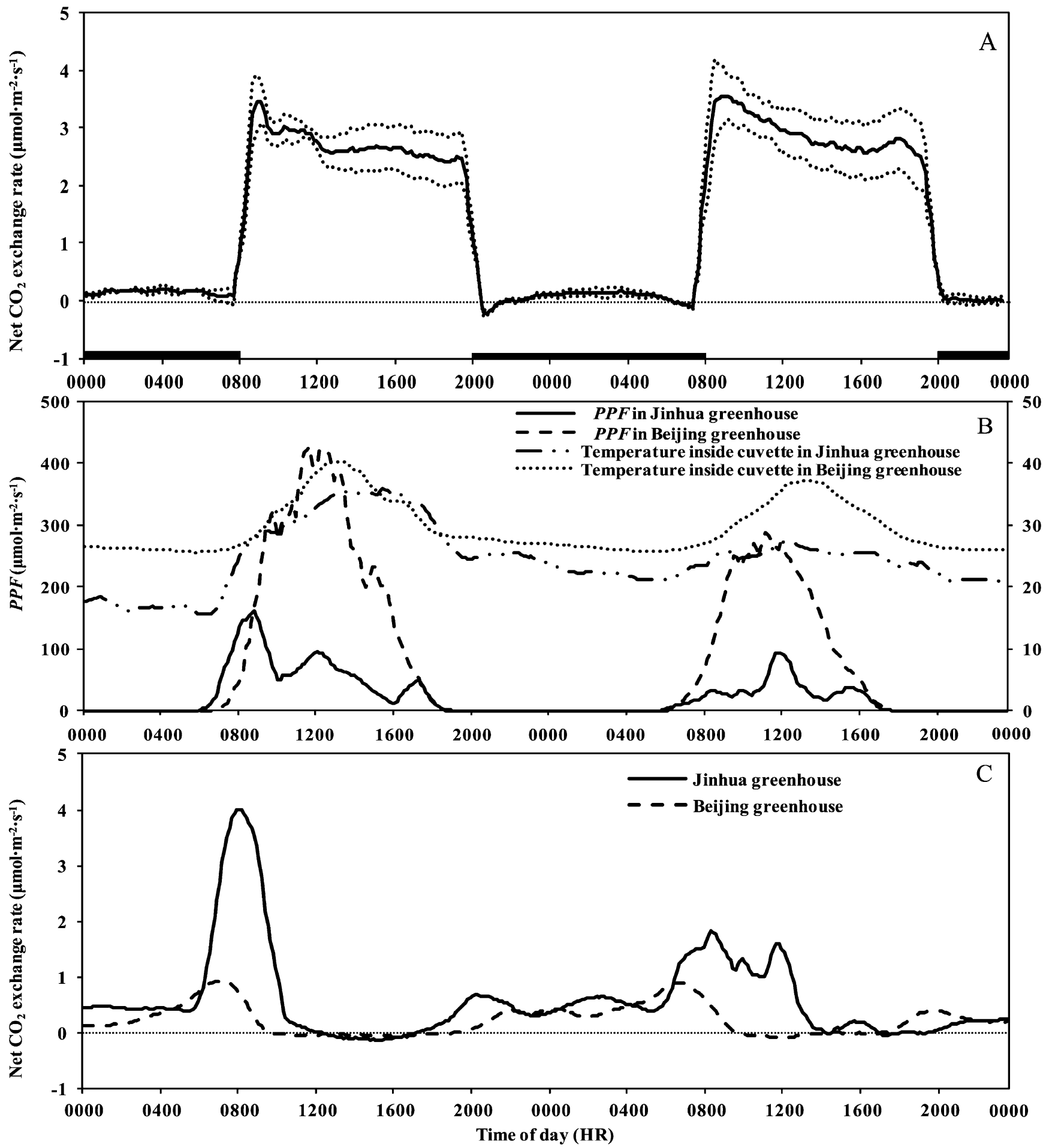

Fig. 2. Time course of net $\mathrm{CO}_{2}$ exchange rates of Dendrobium officinale in the growth chamber on 2 and 3 Sept. 2012 (A), in the Jinhua commercial greenhouse and Beijing research greenhouse on 23 and 24 Apr. 2012 and on 30 and 31 May 2012 (C), and time course of measured photosynthetic photon flux (PPF) and temperatures inside cuvette in the Jinhua and Beijing greenhouses (B). For the growth chamber, $P P F$ was $163.5 \pm 1.4 \mu \mathrm{mol} \cdot \mathrm{m}^{-2} \cdot \mathrm{s}^{-1}$ and daily average air temperature was $26.2 \pm 1.2^{\circ} \mathrm{C}$. Dark bars in the $\mathrm{x}$-axis $(\mathbf{A})$ indicate the dark period in the growth chamber. The dotted lines on top and bottom of the solid line indicate SD $(A, n=2)$. 
rate throughout the light period (Fig. 2A). Positive, low net $\mathrm{CO}_{2}$ exchange rates were detected during the dark period. The daily net $\mathrm{CO}_{2}$ exchange amounts were 110 and $116 \mathrm{mmol} \cdot \mathrm{m}^{-2} \cdot \mathrm{d}^{-1}$, and dark net $\mathrm{CO}_{2}$ exchange percentages to the daily amount of net $\mathrm{CO}_{2}$ exchanges were $6 \%$ and $5 \%$ on 2 and 3 Sept., respectively. The percentage of $\mathrm{CO}_{2}$ exchanges in the dark period to the daily amount of $\mathrm{CO}_{2}$ exchanges reflected the degree of CAM in D. officinale. The results of net $\mathrm{CO}_{2}$ exchange rates indicated a low degree of CAM in D. officinale under relatively stress-free growth chamber conditions.

Net $\mathrm{CO}_{2}$ exchange rates of $D$. officinale grown in the Beijing research greenhouse were measured on a sunny day (30 May 2012) and a cloudy day (31 May 2012). On the sunny day, $P P F$ reached a maximum of $426 \mu \mathrm{mol} \cdot \mathrm{m}^{-2} \cdot \mathrm{s}^{-1}$ and a maximum temperature inside the cuvette of $40.3^{\circ} \mathrm{C}$. On the cloudy day, $P P F$ reached a maximum of $282 \mu \mathrm{mol} \cdot \mathrm{m}^{-2} \cdot \mathrm{s}^{-1}$ and a maximum

Table 1. Relative water content (RWC) of Dendrobium officinale leaves and leaf titratable acidity (TA) accumulated in the dark period under drought-treated and well-watered conditions on Day 1 (6 July 2012), Day 12, and Day $18 .^{z}$

\begin{tabular}{|c|c|c|c|c|c|c|}
\hline \multirow[b]{2}{*}{ Treatment } & \multicolumn{2}{|c|}{ Day 1} & \multicolumn{2}{|c|}{ Day 12} & \multicolumn{2}{|c|}{ Day 18} \\
\hline & $\overline{\mathrm{RWC}(\%)}$ & TA $\left(\mu \mathrm{mol} \cdot \mathrm{g}^{-1} \mathrm{FW}\right)$ & $\overline{\mathrm{RWC}(\%)}$ & $\mathrm{TA}\left(\mu \mathrm{mol} \cdot \mathrm{g}^{-1} \mathrm{FW}\right)$ & $\overline{\mathrm{RWC}(\%)}$ & TA $\left(\mu \mathrm{mol} \cdot \mathrm{g}^{-1} \mathrm{FW}\right)$ \\
\hline Drought-treated & 93.4 & 160.1 & 91.8 & 196.9 & 95.9 & 155.2 \\
\hline Well-watered & 94.9 & 156.1 & 96.5 & 125.3 & 95.5 & 156.6 \\
\hline
\end{tabular}

${ }^{\mathrm{z}}$ The plants were well watered on Day 1 and irrigation was withheld for $12 \mathrm{~d}$ thereafter. At the end of Day 12, plants were rewatered. $\mathrm{y}_{\mathrm{NS}}$ and $*$ indicate nonsignificant and significant at $P \leq 0.05$.

$\mathrm{FW}=$ fresh weight; ANOVA $=$ analysis of variance.
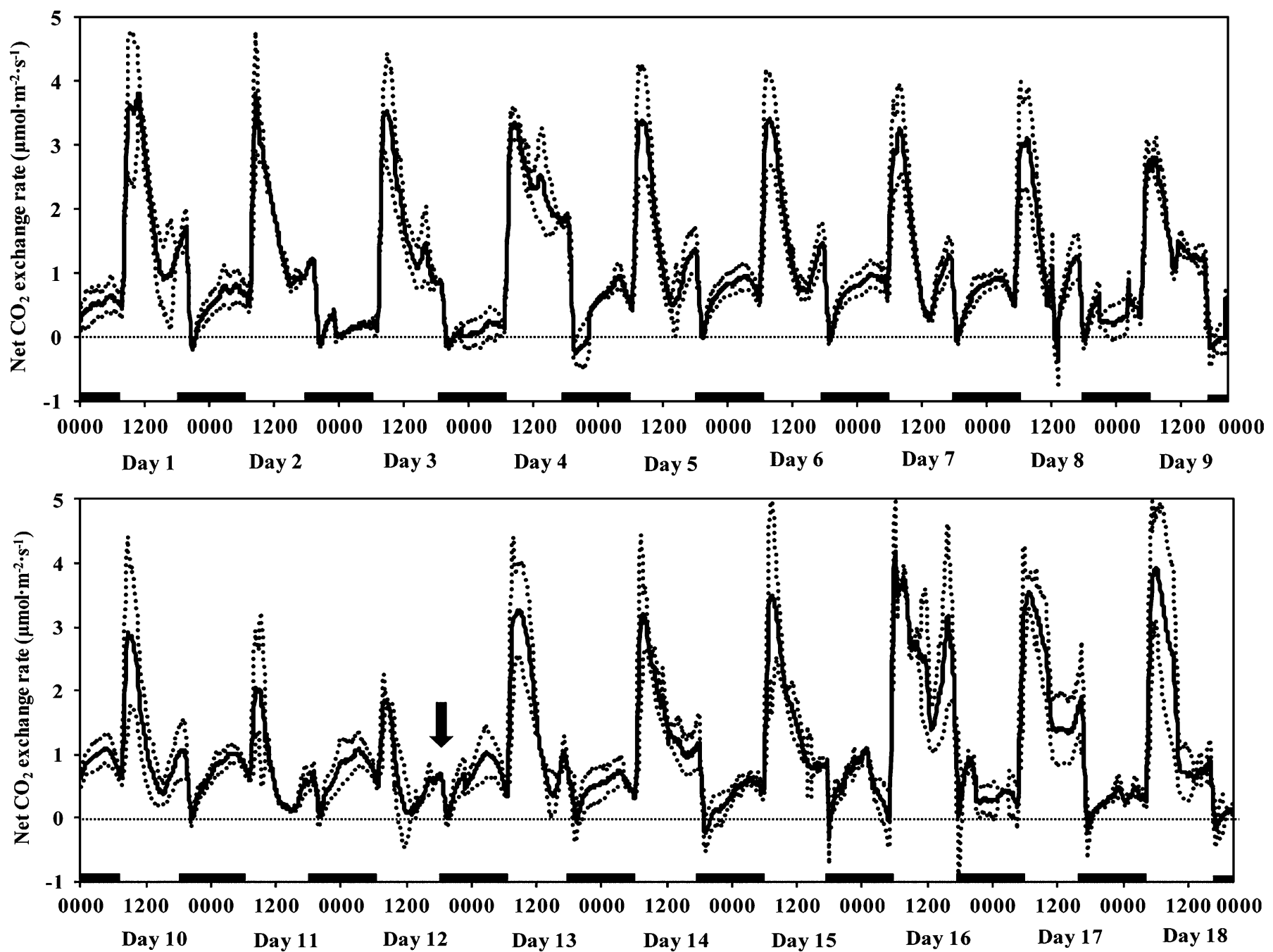

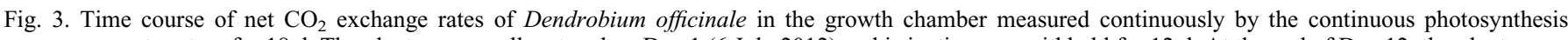
measurement system for $18 \mathrm{~d}$. The plants were well watered on Day 1 (6 July 2012) and irrigation was withheld for $12 \mathrm{~d}$. At the end of Day 12 , the plants were rewatered. Arrow indicates rewatered day, and dark bars in the x-axis indicate the dark period. The x-axis of the lower graph is the continuation of the upper graph, which means the two graphs' $\mathrm{x}$-axes should be connected. The dotted lines on top and bottom of the solid line indicate SD $(\mathrm{n}=2)$. 
cuvette temperature of $37.2{ }^{\circ} \mathrm{C}$ (Fig. 2B). The maximum net $\mathrm{CO}_{2}$ exchange rate of $D$. officinale in the Beijing greenhouse was only $0.9 \mu \mathrm{mol} \cdot \mathrm{m}^{-2} \cdot \mathrm{s}^{-1}$, which occurred at $\approx 0.5 \mathrm{~h}$ after sunrise on both days and then decreased gradually to zero at $\approx 3 \mathrm{~h}$ after sunrise (Fig. $2 \mathrm{C}$ ). The net $\mathrm{CO}_{2}$ exchange rate was negative in the middle of the day. However, net $\mathrm{CO}_{2}$ exchange rate was positive throughout the night. Low net $\mathrm{CO}_{2}$ exchange rates were possibly the result of high light intensity and high temperatures inside the cuvette. High light and high temperature often cause photoinhibition in D. officinale (Ai et al., 2010; $\mathrm{Su}$ and Zhang, 2003), which explains the low net $\mathrm{CO}_{2}$ exchange rates observed. The daily net $\mathrm{CO}_{2}$ exchange amounts were 16 and $21 \mathrm{mmol} \cdot \mathrm{m}^{-2} \cdot \mathrm{d}^{-1}$ and dark net $\mathrm{CO}_{2}$ exchange percentages were $70 \%$ and $66 \%$ on 30 and 31 May 2012, respectively, indicating a high degree of CAM.

Net $\mathrm{CO}_{2}$ exchange rates of $D$. officinale plants grown in the Jinhua commercial greenhouse were measured on a sunny day (23 Apr. 2012) and a rainy day (24 Apr. 2012). A shadecloth was used in the greenhouse from 0900 to $1600 \mathrm{HR}$ on sunny days. The maximum $P P F$ reached 168 and $85 \mu \mathrm{mol} \cdot \mathrm{m}^{-2} \cdot \mathrm{s}^{-1}$ on 23 and 24 Apr., respectively (Fig. 2B). The maximum temperature inside the cuvette reached 35.1 and $27.3^{\circ} \mathrm{C}$ on 23 and 24 Apr., respectively (Fig. 2B). The net $\mathrm{CO}_{2}$ exchange rate reached a maximum of 4.0 and $1.6 \mu \mathrm{mol} \cdot \mathrm{m}^{-2} \cdot \mathrm{s}^{-1}$ at $2 \mathrm{~h}$ after sunrise on both days (Fig. 2C). A higher degree of CAM pattern of $D$. officinale was observed on the sunny day, whereas the duration of positive $\mathrm{CO}_{2}$ exchange rates during the daytime was longer on the rainy day. The daily net $\mathrm{CO}_{2}$ exchange amounts were 53 and $44 \mathrm{mmol} \cdot \mathrm{m}^{-2} \cdot \mathrm{d}^{-1}$ on 23 and $24 \mathrm{Apr}$., and the dark net $\mathrm{CO}_{2}$ exchange percentages were $31 \%$ and $29 \%$, respectively. These results indicated an intermediate degree of CAM in $D$. officinale under the Jinhua greenhouse conditions compared with the plants in the Beijing greenhouse and growth chamber conditions. These differences in net $\mathrm{CO}_{2}$ exchange rates during the day and night periods were the result of the differences in temperatures and light intensities.

$\mathrm{CO}_{2}$ ASSIMILATION PATTERN UNDER DROUGHT AND AFTER REHYDRATION. The relative water content of $D$. officinale leaves without irrigation for $12 \mathrm{~d}$ was $4.7 \%$ less than that of wellwatered plants on the same day (Table 1) and the net $\mathrm{CO}_{2}$ exchange rate decreased as the substrate water content decreased over time (Fig. 3). The daily net $\mathrm{CO}_{2}$ exchange amount on Day 12 was $55 \%$ compared with that on Day 1 (Fig. 4). When the plants were rewatered on Day 12 , net $\mathrm{CO}_{2}$ exchange rate increased again instantly. On Day 18, $6 \mathrm{~d}$ after rewatering, the daily net $\mathrm{CO}_{2}$ exchange amount increased by $51 \%$ compared with that of Day 12. The percentage of $\mathrm{CO}_{2}$ exchanges observed during the dark period increased as drought stress increased or as RWC decreased, but decreased again as plants were rewatered (Fig. 4). The percentage of net $\mathrm{CO}_{2}$ exchange during dark period to the daily amount of $\mathrm{CO}_{2}$ exchanges on Day 12 was 51\%, 189\% higher than Day 1. On Day 12, at RWC of $91.8 \%$, the $\mathrm{CO}_{2}$ assimilation pattern exhibited the typical four phases of a CAM pattern (Fig. 3). After being rewatered, the percentage of net $\mathrm{CO}_{2}$ exchange during the dark period to the daily amount of $\mathrm{CO}_{2}$ exchanges again decreased gradually. By Day 18 , this percentage decreased by $76 \%$ compared with that of Day 12 (Fig. 4). A similar response was reported for Kalanchö porphyrocalyx and Kalanchö̈ mimiata (Brulfert et al., 1996). Drought stress increased $\mathrm{CO}_{2}$ assimilation in the dark period, representing a short-term response mechanism to compensate for reduced diurnal supply of carbon and maintain a positive carbon balance (de Mattos and Lüttge, 2001; Dodd et al., 2002).

The accumulation of titratable acidity during the dark period for drought-stressed and well-watered $D$. officinale plants did not differ on Day 1 or Day 18. However, drought-stressed plants accumulated 57\% more titratable acidity than well-watered plants on Day 12 (Table 1). These results indicate that the titratable acidity accumulation during the dark period increased as substrate water content decreased and decreased again as substrate water content increased after being rewatered. Talinum triangulare had a dark titratable acidity accumulation of $6 \mu \mathrm{mol} \cdot \mathrm{g}^{-1} \mathrm{FW}$ when it was in the $\mathrm{C} 3$ assimilation pattern, whereas its dark titratable acidity accumulation increased to $100 \mu \mathrm{mol} \cdot \mathrm{g}^{-1} \mathrm{FW}$ when the plant switched to CAM (Herrera

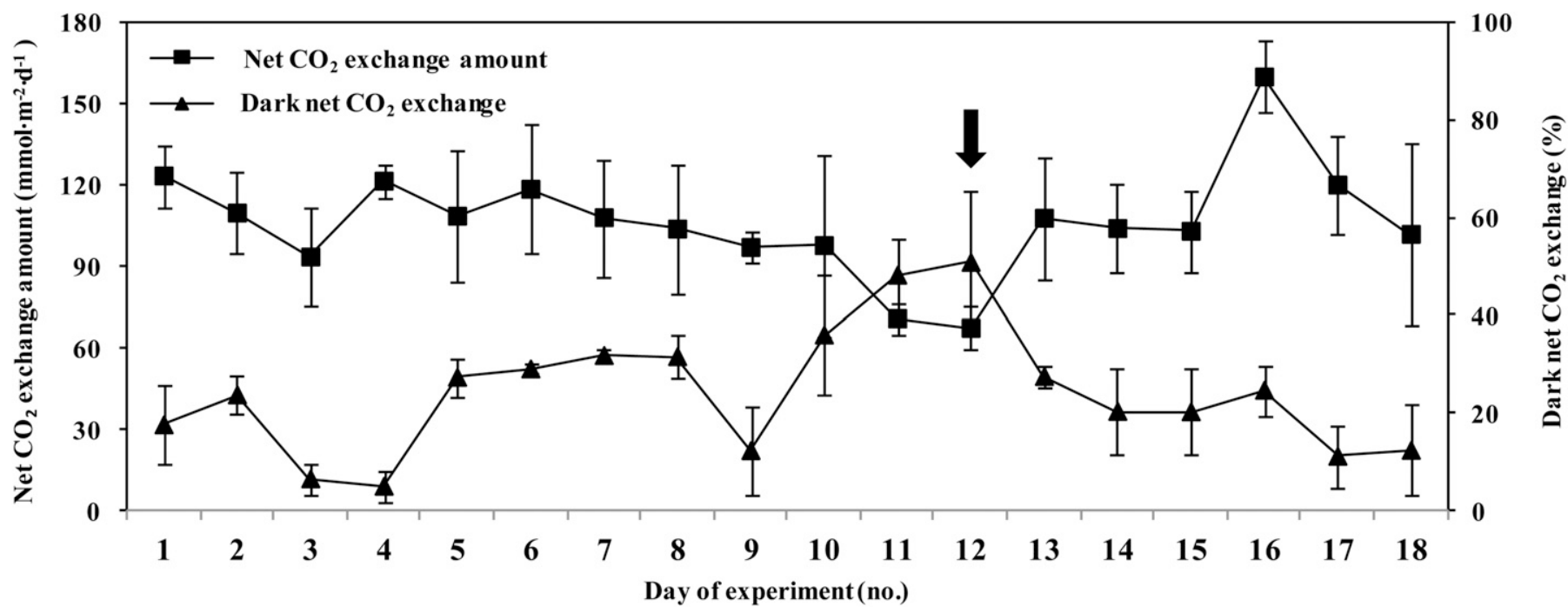

Fig. 4. Daily (total) net $\mathrm{CO}_{2}$ exchange amount of Dendrobium officinale (square) and the daily net $\mathrm{CO}_{2}$ exchange amount during the dark periods accumulated over $24 \mathrm{~h}$ expressed as the proportion of the total daily amount in percentage (triangle, accumulated in $24 \mathrm{~h}$ ). The plants were well watered on Day 1 (6 July 2012 ) and irrigation was withheld for $12 \mathrm{~d}$. At the end of the Day 12, the plants were rewatered. Arrow indicates rewatered day. Vertical bars represent SD $(\mathrm{n}=2)$. 
et al., 1991). Similarly, Clusia minor leaves had more titratable acid accumulation under dry than under wet conditions (Borland et al., 1992, 1998). It is obvious that drought stress induces CAM in facultative CAM species. In D. officinale, the gradual decrease in the substrate moisture content provided gradual drought stress, which led to the plant $\mathrm{CO}_{2}$ assimilation pattern to switch from dominant $\mathrm{C} 3$ to $\mathrm{CAM}$. After rewatering, the $\mathrm{CO}_{2}$ assimilation pattern reversed from CAM to dominant $\mathrm{C} 3$.
$\mathrm{CO}_{2}$ ASSIMILATION PATTERN UNDER DIFFERENT LIGHT-DARK CYCLES. The net $\mathrm{CO}_{2}$ exchange rate of $D$. officinale increased rapidly after the onset of the light period and decreased again in 4 to $6 \mathrm{~h}$ (Figs. 2A and 2C). Therefore, shortening the light-dark cycles from $24 \mathrm{~h}$ to $8 \mathrm{~h}$ or $12 \mathrm{~h}$ may increase the daily net $\mathrm{CO}_{2}$ exchange rate. When light and dark periods were shortened, net $\mathrm{CO}_{2}$ exchange rates in the dark period changed from positive to negative (Fig. 5A-C). At the 8-h cycle, there was no positive
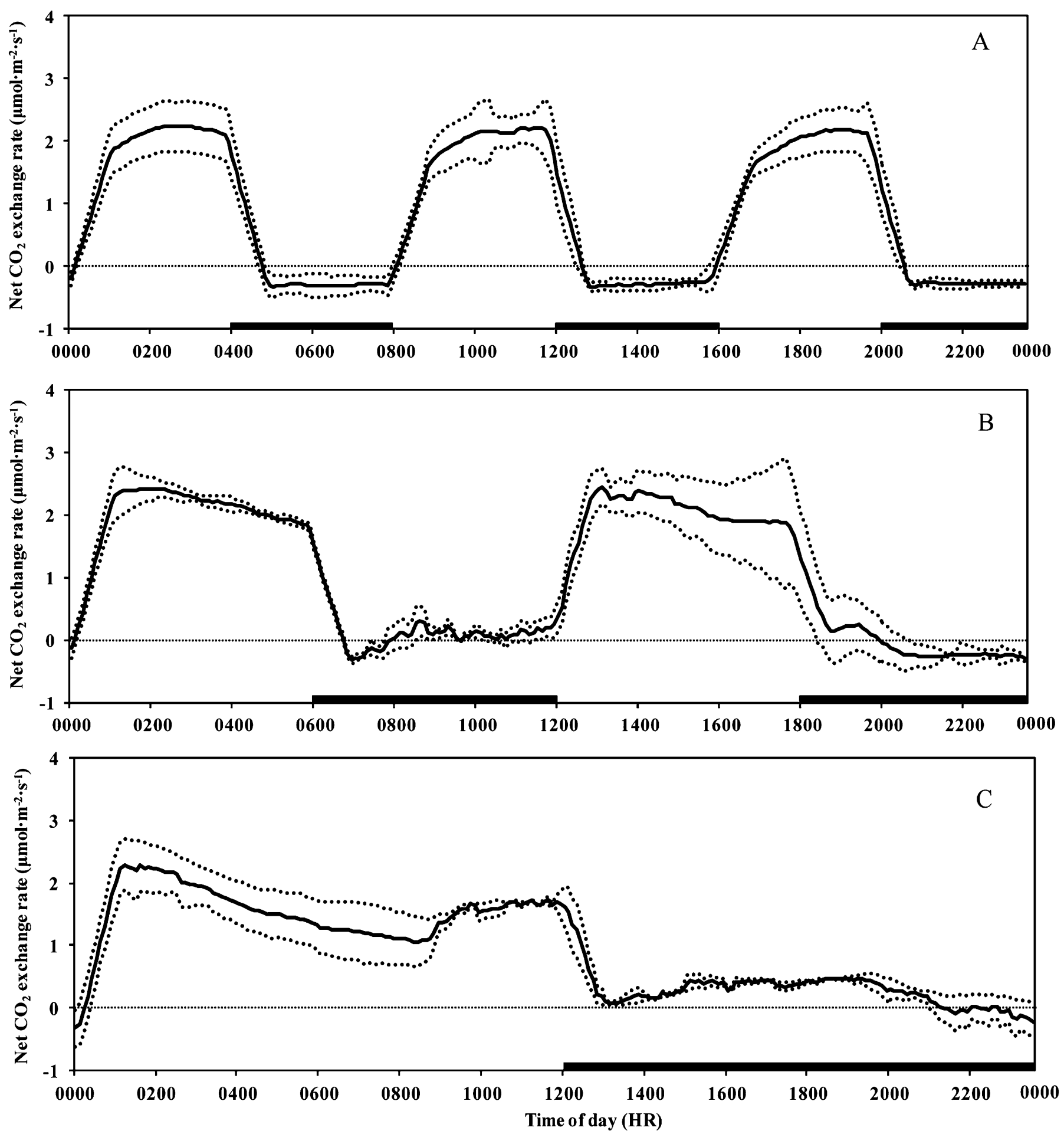

Fig. 5. Time course of net $\mathrm{CO}_{2}$ exchange rates of Dendrobium officinale in 8-h (A, $4 \mathrm{~h}$ light and $4 \mathrm{~h}$ dark), $12-\mathrm{h}(\mathbf{B}, 6 \mathrm{~h}$ light and $6 \mathrm{~h}$ dark $)$, and $24-\mathrm{h}(\mathbf{C}, 12 \mathrm{~h}$ light and 12 dark) cycles. Dark bars in the $\mathrm{x}$-axis indicate the dark period. The dotted lines on top and bottom of the solid line indicate $\mathrm{SD}(\mathrm{n}=2)$. 
net $\mathrm{CO}_{2}$ exchange rate in the dark period, and plants exhibited a $\mathrm{C} 3 \mathrm{CO}_{2}$ assimilation pattern (Fig. 5A).

The average leaves titratable acidity of $D$. officinale plants grown under a 8-h cycle at $0400,0800,1200,1600$, and $2000 \mathrm{HR}$ was $167.4 \pm 5.2 \mu \mathrm{mol} \cdot \mathrm{g}^{-1} \mathrm{FW}$ with small variations among sampling times (data not shown), which indicated that D. officinale may have only a C3 pathway under an 8-h cycle.

The effect of light and dark period cycles and length of photoperiod on $\mathrm{CO}_{2}$ assimilation pattern varied with species and other factors. For example, the tropical species K. blossfeldiana exhibited only a CAM pattern during short days (Brulfert et al., 1988). For the subtropical Portulacaria afra, long days are more inductive of a CAM pattern in well-watered plants, whereas drought-stressed plants have a typical CAM pattern regardless of photoperiod (Guralnick et al., 1984). More studies are needed for $D$. officinale to identify the optimal light and dark period cycle and length of the photoperiod along with other environmental conditions, which lead to the switching between $\mathrm{C} 3$ and CAM pathways.

$\mathrm{Su}$ and Zhang (2003) measured the net $\mathrm{CO}_{2}$ exchange rates of $D$. officinale plants every $2 \mathrm{~h}$ using the portable photosynthesis system (LI-6400; LI-COR). They reported that D. officinale had a typical CAM on sunny days, C3 on rainy days, and an intermediate pathway between C3 and CAM on cloudy days. In our study, a higher degree of CAM was also observed on a sunny day, whereas the $\mathrm{CO}_{2}$ assimilation pattern on the rainy day was a low-degree CAM but was somewhat different from that on a sunny day (Fig. 2C). Our results indicated that the $\mathrm{CO}_{2}$ assimilation pattern of $D$. officinale was affected by the environmental conditions such as temperature and light intensity. In other words, the degree of CAM in D. officinale changed and adapted to changing environmental conditions. The intermediate pathway between C3 and CAM reported by $\mathrm{Su}$ and Zhang (2003) might indicate the different degrees of CAM as found in our studies. As a result of the unique $\mathrm{CO}_{2}$ assimilation pattern in D. officinale, it is inappropriate to compare with other studies without knowing the exact environmental conditions.

In the growth chamber, the majority of $\mathrm{CO}_{2}$ exchange was observed in the light period but there was still a small positive amount of $\mathrm{CO}_{2}$ exchange in the dark period. The $\mathrm{CO}_{2}$ assimilation pattern of $D$. officinale exhibited concomitant CAM and C3 photosynthetic pathways when grown in the growth chamber. In addition, the accumulation in leaf titratable acidity for CAM plants was observed in plants under well-watered growth chamber conditions (Table 1). In facultative species, CAM may be induced by environmental factors such as high PPF (Maxwell, 2002), temperature (Haag-Kerwer et al., 1992), and the relative air humidity (Schmitt et al., 1988). The dark net $\mathrm{CO}_{2}$ exchange percentages of the $2 \mathrm{~d}$ in the Beijing greenhouse were 10.7 and 12.2 times that in the growth chamber. The degree of CAM in D. officinale was different when placed in the Beijing greenhouse with high temperatures and high light intensity conditions and in the relatively stress-free growth chamber. Plants under the high temperatures and high light intensity conditions (greenhouse in this study) had stronger CAM compared with the plants grown in the relatively nonstressed growth chamber conditions.

Changes in $\mathrm{CO}_{2}$ assimilation pattern and leaf titratable acidity in D. officinale plants were similar to those of well-watered facultative CAM plant $K$. porphyrocalyx and $K$. mimiata (Brulfert et al., 1996). The $\mathrm{CO}_{2}$ assimilation pattern of well-watered facultative CAM plants T. triangulare (Herrera et al., 1991), Guzmania monostachia (Maxwell et al., 1994), and Tillandsia utriculata (Stiles and Martin, 1996) exhibited a C3 pattern (no positive net $\mathrm{CO}_{2}$ exchange rates in the dark period), different from $D$. officinale in the $\mathrm{CO}_{2}$ assimilation pattern, but the accumulation of the leaf titratable acidity in the dark period was similar. The accumulation of titratable acidity during the dark period indicates the activity of phosphoenolpyruvate carboxylase (PEPC), whereas net $\mathrm{CO}_{2}$ exchange rates during the dark period depend on the dark respiration rate and the $P E P C \mathrm{CO}_{2}$ fixing rate. The positive net $\mathrm{CO}_{2}$ exchange rates in $D$. officinale during the dark period indicated that dark respiration rate was smaller than the PEPC $\mathrm{CO}_{2}$ fixation rate, whereas dark respiration rates for $T$. triangulare, $G$. monostachia, and T. utriculata were greater than their PEPC fixation rates.

The $\mathrm{CO}_{2}$ assimilation pattern of $D$. officinale in the relatively stress-free condition was different from typical facultative CAM plants such as $M$. crystallinum (Eastmond and Ross, 1997; Winter and Holtum, 2007) and C. minor (Borland et al., 1993) because there were no titratable acidity accumulation in leaves during the dark period when $M$. crystallinum and C. minor were well watered. Because leaf titratable acidity accumulated in the dark period, it is difficult to confirm a $\mathrm{C} 3$ pathway alone for $D$. officinale under relatively stress-free and a 24-h light-dark cycle conditions as observed in well-watered facultative CAM plants $M$. crystallinum and $C$. minor. For D. officinale, C3 and CAM pathways might coexist under relatively stress-free conditions (growth chamber conditions in this study).

\section{Conclusion}

Based on the net $\mathrm{CO}_{2}$ exchanges rates under various conditions and titratable acidity accumulation, $D$. officinale had concomitant CAM and C3 pathways when grown in the relatively non-stressed growth chamber conditions and have higher net $\mathrm{CO}_{2}$ exchange rates compared with greenhouse conditions with suboptimal temperatures and light intensities. Drought stress and rewatering induced a switch of the $\mathrm{CO}_{2}$ assimilation patterns from $\mathrm{C} 3$ dominant to the CAM pathway and from CAM-dominant to the C3 pathway. Growth of $D$. officinale may be promoted by controlling the growing environment to induce the $\mathrm{C} 3$ pathway to increase the daily net $\mathrm{CO}_{2}$ assimilation amount.

\section{Literature Cited}

Ai, J., N. Yan, H. Hu, and S. Li. 2010. Effects of temperature on the growth and physiological characteristics of Dendrobium officinale (Orchidaceae). Acta Botanica Yunnanica 32:420-426 [in Chinese with English abstract].

Bao, S., D. He, and S. Guo. 2007. Suitable lighting intensity of Dendrobium officinale in vitro in closed plant factory under artificial lighting. Chinese Agr. Sci. Bul. 23:469-473 [in Chinese with English abstract].

Borland, A.M., H. Griffiths, M.S.J. Broadmeadow, M.C. Fordham, and C. Maxwell. 1993. Short term changes in carbon-isotope discrimination in the C3-CAM intermediate Clusia minor L. growing in Trinidad. Oecologia 95:444-453.

Borland, A.M., H. Griffiths, C. Maxwell, M.S.J. Broadmeadow, N.M. Griffiths, and J.D. Barnes. 1992. On the ecophysiology of the Clusiaceae in Trinidad: Expression of CAM in Clusia minor L. during the transition from wet to dry season and characterization of three endemic species. New Phytol. 122:349-357. 
Borland, A.M., L.I. Técsi, R.C. Leegood, and R.P. Walker. 1998. Inducibility of crassulacean acid metabolism (CAM) in Clusia species: Physiological/biochemical characterisation and intercellular localization of carboxylation and decarboxylation processes in three species which exhibit different degrees of CAM. Planta 205:342351.

Brulfert, J., M. Kluge, S. Güçlü, and O. Queiroz. 1988. Interaction of photoperiod and drought as CAM inducing factors in Kalanchö blossfeldiana Poelln., cv. Tom Thumb. J. Plant Physiol. 133:222227.

Brulfert, J., D. Ravelomanana, S. Güçlü, and M. Kluge. 1996. Ecophysiological studies in Kalanchoë porphyrocalyx (Baker) and $K$. mimiata (Hils et Bojer), two species performing highly flexible CAM. Photosynth. Res. 49:29-36.

de Mattos, E.A. and U. Lüttge. 2001. Chlorophyll fluorescence and organic acid oscillations during the transition from CAM to C3-photosynthesis in Clusia minor L. (Clusiaceae). Ann. Bot. (Lond.) 88:457-463.

Dodd, A.N., A.M. Borland, R.P. Haslam, H. Griffiths, and K. Maxwell. 2002. Crassulacean acid metabolism: Plastic, fantastic. J. Expt. Bot. 53:569-580.

Eastmond, P.J. and J.D. Ross. 1997. Evidence that the induction of crassulacean acid metabolism by water stress in Mesembryanthemum crystallinum (L.) involves root signaling. Plant Cell Environ. 20:1559-1565.

$\mathrm{Fu}, \mathrm{C}$. and C. Hew. 1982. Crassulacean acid metabolism in orchids under water stress. Bot. Gaz. 143:294-297.

Gao, T., J. Si, Y. Zhu, and H. Huang. 2012. Effects of light quality and germplasm on growth and effective ingredients of Dendrobium officinale germchit. China J. Chinese Materia Medica 37:198-201 [in Chinese with English abstract].

Guralnick, L.J., P.A. Rorabaugh, and Z. Hanscom. 1984. Seasonal shifts of photosynthesis in Portulacaria afra (L.) Jacq. Plant Physiol. 76:643-646.

Haag-Kerwer, A., A.C. Franco, and U. Lüttge. 1992. The effect of temperature and light on gas exchange and acid accumulation in the C3-CAM plant Clusia minor L. J. Expt. Bot. 43:345-352.

Herrera, A., J. Delgado, and I. Paraguatey. 1991. Occurrence of inducible crassulacean acid metabolism in leaves of Talinum triangulare (Portulacaceae). J. Expt. Bot. 42:493-499.

Larcher, W. 1995. Plant physiological ecology. 3rd Ed. SpringerVerlag, Berlin, Germany.

Li, J., S. Li, D. Huang, X. Zhao, and G. Cai. 2011. Advances in the resources, constituents and pharmacological effects of Dendrobium officinale. Sci. Technol. Rev. 29:74-79 [in Chinese with English abstract].

Mao, L. 2008. Photosynthetic characters and medicinal ingredients of Dendrobium candidum under different cultivation conditions. MS thesis, Zhejiang Normal Univ., Jinhua, China [in Chinese with English abstract].

Maxwell, C., H. Griffiths, and A.J. Young. 1994. Photosynthetic acclimation to light regime and water stress by the C3-CAM epiphyte Guzmania monostachia: Gas-exchange characteristics, photochemical efficiency and the xanthophyll cycle. Funct. Ecol. 8:746-754.
Maxwell, K. 2002. Resistance is useful: Diurnal patterns of photosynthesis in C-3 and crassulacean acid metabolism epiphytic bromeliads. Funct. Plant Biol. 29:679-687.

Nobel, P.S. 1991. Achievable productivities of certain CAM plants: Basis for high values compared with C3 and C4 plants. New Phytol. 119:183-205.

Osmond, C.B. 1978. Crassulacean acid metabolism: A curiosity in context. Annu. Rev. Plant Physiol. 29:379-414.

Rascher, U., B. Blasius, F. Beck, and U. Lüttge. 1998. Temperature profiles for the expression of endogenous rhythmicity and arrhythmicity of $\mathrm{CO}_{2}$ exchange in the CAM plant Kalanchö daigremontiana can be shifted by slow temperature changes. Planta 207:76-82.

Ren, J., Y. Wan, and Z. Peng. 2010. Measurement of malic acid diel [sic] fluctuation of leaves in three dendrobia. Acta Agriculturae Universitatis Jiangxiensis (Natural Sci. Ed.) 32:547-552 [in Chinese with English abstract].

Schmitt, A.H., H.S.J. Lee, and U. Lüttge. 1988. The response of C3CAM tress, Clusia rosea, to light and water stress. I. Gas exchange characteristics. J. Expt. Bot. 39:1581-1590.

Sekizuka, F., A. Nose, Y. Kawamitu, T. Akinaga, C. Taira, and A. Onaha. 1992. Effect of day/night temperature conditions on $\mathrm{CO}_{2}$ exchange rate and $\mathrm{CO}_{2}$ balance of Dendrobium ekapol [sic] Panda No. 1. Acta Hort. 292:187-192.

Silvera, K., L.S. Santiago, and K. Winter. 2005. Distribution of crassulacean acid metabolism in orchids of Panama: Evidence of selection for weak and strong modes. Funct. Plant Biol. 32:397-407.

Sinclair, R. 1984. Water relations of tropical epiphytes. III. Evidence for crassulacean acid metabolism. J. Expt. Bot. 35:1-7.

Stiles, K.C. and C.E. Martin. 1996. Effects of drought stress on $\mathrm{CO}_{2}$ exchange and water relation in the CAM epiphyte Tillandsia utriculata (Bromeliaceae). J. Plant Physiol. 149:721-728.

$\mathrm{Su}, \mathrm{W}$. and G. Zhang. 2003. The photosynthesis pathway in leaves of Dendrobium officinale. Acta Phytoecol. Sin. 27:631-637 [in Chinese with English abstract].

Winter, K., M. Garcia, and J.A.M. Holtum. 2009. Canopy $\mathrm{CO}_{2}$ exchange of two neotropical tree species exhibiting constitutive and facultative CAM photosynthesis, Clusia rosea and Clusia cylindrica. J. Expt. Bot. 60:3167-3177.

Winter, K. and J.A.M. Holtum. 2007. Environment or development? Lifetime net $\mathrm{CO}_{2}$ exchange and control of the expression of crassulacean acid metabolism in Mesembryanthemum crystallinum. Plant Physiol. 143:98-107.

Winter, K., B.J. Wallace, G.C. Stocker, and Z. Roksandic. 1983. Crassulacean acid metabolism in Australian vascular epiphytes and some related species. Oecologia 57:129-141.

Yang, J., C. Chen, X. Han, X. Li, and H.P. Liebig. 2002. Measurement of vegetable leaf area using digital image processing techniques. Trans. Chinese Soc. Agr. Eng. 18:155-158 [in Chinese with English abstract].

Zhang, Y., J. Guo, T. Luo, X. Zhang, and Y. Yi. 2013. Effect of illumination intensity under different temperature and humidity conditions on photosynthetic rate of Dendrobium candidum. Northern Hort. 8:119-122 [in Chinese with English abstract]. 